\title{
Sweetened beverage consumption is a risk factor for depressive symptoms among adolescents living in Boston, Massachusetts, USA
}

\author{
Roman Pabayo ${ }^{1,2, *}$, Joice Dias ${ }^{1,3}$, David Hemenway ${ }^{4}$ and Beth E Molnar ${ }^{5}$ \\ ${ }^{1}$ Department of Community Health Sciences, School of Community Health Sciences, University of Nevada, Reno, \\ Lombardi Recreation Center 203, MS 0274, 1664 North Virginia Street, Reno, NV 89557, USA: ²Department of \\ Social Behavioral Sciences, Harvard T.H. Chan School of Public Health, Boston, MA, USA: ${ }^{3}$ Medical School, Federal \\ University of Minas Gerais, Belo Horizonte, MG, Brazil: ${ }^{4}$ Department of Health Policy and Management, \\ Harvard T.H. Chan School of Public Health, Boston, MA, USA: ${ }^{5}$ Bouvé College of Health Sciences, Northeastern \\ University, Boston, MA, USA
}

Submitted 6 December 2015: Final revision received 28 May 2016: Accepted 8 June 2016: First published online 13 July 2016

\begin{abstract}
Objective: To investigate the relationship between sweetened beverage consumption and depressive symptoms among adolescents.

Design: In a cross-sectional study, adolescents were asked how often they drank soda and fruit drinks in the past $7 \mathrm{~d}$. Depressive symptoms were measured using a brief adapted version of the Modified Depression Scale. Summation scores were standardized using the $Z$-transformation. We used multilevel multiple linear regression models to estimate the association between soda and fruit drink consumption and depressive symptoms.

Setting: The 2008 Boston Youth Survey.

Subjects: Adolescents ( $n$ 1878), high-school students in grades 9-12 of Boston public schools, Massachusetts, USA.

Results: Compared with those who never drank soda in the past $7 \mathrm{~d}$, those who consumed soda 2-6 times/week $(\beta=0 \cdot 18 ; 95 \%$ CI $0 \cdot 04,0 \cdot 32)$ or $\geq 1$ times/d $(\beta=0.29 ; 95 \%$ CI $0 \cdot 13,0.45)$ had higher depressive symptoms. Similarly, those who consumed fruit drinks 2-6 times/week $(\beta=0 \cdot 14 ; 95 \%$ CI $0 \cdot 00,0 \cdot 28)$ and those who consumed $\geq 1$ times/d $(\beta=0 \cdot 22 ; 95 \%$ CI $0 \cdot 04,0 \cdot 40)$ had higher depressive symptoms.

Conclusions: Frequent consumption of both soda and fruit drinks is associated with greater depressive symptoms among adolescents.
\end{abstract}

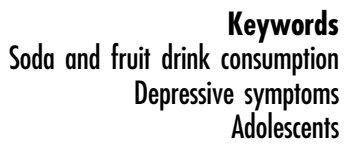

Depression among teens is a major public health concern in the USA. According to recent evidence, the prevalence of a lifetime major depressive episode among adolescents aged 12-17 years is $7 \cdot 7$ (95\% CI 7.3, 8.2) \% and $18 \cdot 2$ (95\% CI $17 \cdot 5$, $18.9) \%$ among boys and girls, respectively ${ }^{(1)}$. Furthermore, an estimated $30 \%$ of adolescents reported experiencing symptoms of depression, such as feeling sad or hopeless ${ }^{(2)}$. Girls, in comparison to boys, are more likely to experience depression $^{(1)}$. In comparison to white students, Hispanic students are more likely to report depressive symptoms, while black students are less likely ${ }^{(3)}$. Teens from lower socio-economic status backgrounds are more likely to experience depression $^{(4)}$. For example, the populationattributable risk for income and education on depression is $26 \%$ and $40 \%{ }^{(5)}$, respectively. Public health impacts include suicide, which was the second leading cause of death among adolescents aged 12-17 years in $2010^{(1)}$.
Sugar-sweetened beverages are those that contain caloric sweeteners and typically include soft drinks, soda, pop, soda pop, fruit juices and fruit drinks. A soft drink is a beverage that typically contains carbonated water, a sweetener, and a natural or artificial flavouring. The terms 'sodas' and 'pops' have been used interchangeably with 'soft drinks'. Fruit juices contain $100 \%$ fruit juice and provide essential vitamins and minerals. Fruit drinks do not contain very much fruit juice and do not contain vitamins and minerals. Recent evidence identifies that regular soda consumption has been increasing among children in the USA and Europe $^{(6-10)}$. Furthermore, the proportion of daily energy from sweetened beverages increased significantly from $11.8 \%$ in 1965 to $21.0 \%$ in 2002 in the USA. This has led health professionals to recommend that children limit intake of beverages high in sugar such as regular soda and fruit juices from their daily dietary intake ${ }^{(6)}$. In the USA, 
researchers have observed associations between soda consumption and adverse behavioural problems among children and adolescents ${ }^{(1-13)}$. For example, soda consumption was associated with withdrawn behaviour and aggression in 5-year-olds ${ }^{(13)}$ and with violence perpetration and suicidal behaviour among adolescents ${ }^{(11,12)}$.

Sugar consumption has been identified as a risk factor for depression $^{(14)}$. One theoretical biological mechanism by which sugar leads to depression involves the reduction of brain-derived neurotrophic factor ${ }^{(15,16)}$. Previous studies have identified the relationship between soda consumption and depression, specifically among adults ${ }^{(17-19)}$. However, research is limited in adolescence, a particular period when the human brain is undergoing development and might be sensitive to high sugar intake. Additionally, the relationship between the consumption of other sweetened beverages, such as fruit drinks, and depressive symptoms has yet to be investigated. An observed association could highlight the importance of recognizing that fruit drinks, even though perceived to be healthy, can be detrimental to the mental health of adolescents.

Although several studies have identified high soda consumption as a risk factor for depression among adults ${ }^{(17-19)}$, limited evidence exists that identifies this relationship among adolescents. To our knowledge, only one study has investigated this relationship among adolescents ${ }^{(20)}$. In a study among Norwegian adolescents, researchers observed a J-shaped relationship between soda consumption and mental distress ${ }^{(20)}$. More studies among adolescents are warranted, especially among US teens, where the prevalence of daily soda consumption is high in comparison to other OECD (Organisation for Economic Co-operation and Development) countries. Furthermore, the association between mental health and sources of sweetened beverages other than sodas, such as fruit drinks, needs to be investigated. One previous study identified different sociodemographic characteristics associated with differing sweetened beverages ${ }^{(21)}$. For example, children from lower socio-economic backgrounds were significantly more likely to consume sodas in comparison to those from high socioeconomic backgrounds, and girls were significantly less likely to consume soft drinks than boys ${ }^{(21)}$. However, sex and socio-economic status were not associated with fruit juice consumption $^{(21)}$.

The current study addresses the dearth in the literature by conducting analyses among adolescents to identify the association between soda and fruit drink consumption and depressive symptoms. We hypothesize that students who consume high amounts of soda and fruit drinks have higher depressive symptoms.

\section{Methods}

Data come from the 2008 Boston Youth Survey (BYS), a biennial survey of high-school students in grades 9-12 in
Boston public schools $(n \text { 31 })^{(22,23)}$, Massachusetts, USA. Of the eligible schools, twenty-two agreed to participate (71\%). The final sample of schools was representative of all public schools in the Boston area in terms of race/ ethnicity of the students, school drop-out rates and other variables $^{(24)}$.

A unique list of classrooms was obtained from each school and classrooms stratified by grade were randomly selected for participation in the BYS until 100-120 students in each school were identified. All students in randomly selected classrooms were invited to participate ${ }^{(24)}$. We used passive parental consent and students were also free to decline to participate at any time before or during the survey administration. The response rate was $69 \%$, reflecting primarily students who were absent on the day of administration, which yielded a sample size of 1878 students. Of the 1878 students, complete data were available for $1314 / 1878=70 \cdot 0 \%$ of students. We used multiple imputations to replace missing individual-level data. Students who did not provide their residential location were excluded. As a result, complete data within the imputed data set were available for $1611 / 1878=85 \cdot 8 \%$ of students. We imputed missing values within five copies of the data set. We then used multilevel regression analyses to fit the model of interest to each of the imputed data sets. Next, we averaged the estimates to obtain estimated associations $^{(25)}$. Those with missing data were more likely to be male, black, older and to have immigrated to the USA within the last 4 years.

\section{Data collection}

The BYS team of investigators developed the questionnaire, using reliable and valid scales to measure behaviours. We emphasized violence exposure. During the spring of 2008, a paper-and-pencil survey was administered in classrooms by trained staff. The Office of Human Research Administration at the Harvard School of Public Health approved all data collection procedures.

\section{Study variables}

Individual-level covariates in the study were students' gender, age, nativity (US born, foreign born arrived $\leq 4$ years, foreign born arrived $>4$ years) and race/ethnicity (white, black, Asian, Hispanic, other).

Depressive symptoms were measured using a brief adapted version of the Modified Depression Scale (MDS), which has been described elsewhere ${ }^{(26)}$. Briefly, students were asked to report the frequency of five symptoms in the past month: 'In the past month, how often ...': (i) '... were you very sad?'; (ii) '... were you grouchy or irritable or in a bad mood?'; (iii) '... did you feel hopeless about the future?'; (iv) '... did you sleep a lot more or less than usual?'; and (v) '... did you have difficulty concentrating on your school work?'. Response options included 'never' $(=1)$, 'rarely' (=2), 'sometimes' (=3), 'often' (=4) and 'always' $(=5)$. Total scores were calculated by summing 
items among participants who had complete responses for all five items (range: 5-25). Scores were standardized using the $Z$-transformation. BYS data were used to evaluate psychometrics (Cronbach's $\alpha=0.79$ ), reliability and known-group validity ${ }^{(26)}$.

\section{Sweetened beverage consumption}

The BYS collected information on soda and sweet drink consumption, but NOT fruit juice consumption. For both soda (not including diet soda) and sweetened fruit drink consumption, students were asked: 'In the past 7 days, how often did you drink ... (1 can or glass; count $20 \mathrm{oz}$ bottles as 2 cans)?'. Response options included 'never or less than 1 can', ' 1 can in the past 7 days', ' $2-4$ cans in the past 7 days', '5- 6 cans in the past 7 days', ' 1 can per day', ' 2 cans per day' and ' 3 or more cans per day'. Response options were categorized into never, 1 time/week, 2-6 times/week and $\geq 1$ times/d.

\section{Area-level economic deprivation}

Since individual-level income information was not collected, we used an area-level approximation of the socio-economic environment. Students were asked the nearest cross-street of their residence for geocoding to US Census tracts. Data from the US Census American Community Survey in 2008 were used to characterize neighbourhood clusters of Census tracts. These neighbourhood clusters were formed by working with key informants from Boston to identify thirty-eight socially meaningful neighbourhood clusters.

Economic deprivation, which is a socio-economic score, was created using principal components analysis. US Census indicators included for this score were the proportion of residents living below the poverty level, the proportion of households receiving public assistance and the proportion of families with a female head of household (Cronbach's $\alpha=0 \cdot 84$ ). A higher score was indicative of greater economic deprivation or poverty. Tertiles of the neighbourhood economic deprivation were used to categorize economic deprivation into low, moderate and high.

\section{Statistical analysis}

Since students were nested within neighbourhoods, we used multilevel modelling to investigate the relationship between sweetened beverage consumption and depressive symptoms. Multilevel models are a generalization of the linear model used in traditional analysis. Further information regarding the use of this analysis in public health research is available ${ }^{(27)}$.

To determine whether there were sociodemographic differences associated with soft drink and fruit drink consumption, multilevel logistic regression models were run to determine the relationships of gender, age, race, nativity and neighbourhood deprivation with daily consumption of soda, daily consumption of fruit drinks, no consumption of soda and no consumption of fruit drinks.
To investigate the association of soda and fruit drink consumption with depressive symptoms, a sequence of multilevel linear models was conducted. First, a set of analyses involved estimating the null model. The null model allowed us to calculate the intraclass correlation coefficient, which allowed us to determine the proportion of variance explained at the neighbourhood and at the individual levels. Then potential confounders were added. Cross-level economic deprivation $\times$ sweetened beverage consumption, race $\times$ sweetened beverage consumption and gender $\times$ sweetened beverage consumption interaction terms were added to determine if the association between sweetened beverage and depressive symptoms differed across socio-economic groups and gender. Since interaction terms were not significant, findings were not presented. We ran the analyses twice, first using the case-complete data set and second with the multiply imputed data set. Since the results in the case-complete analyses were consistent with the analysis using the multiply imputed data set, only results from the latter analyses are presented.

\section{Results}

The characteristics of the students participating in the BYS are found in Table 1. Characteristics of the case-complete and imputed samples are provided. Overall, the sample had $53.4 \%$ females, $42.6 \%$ were black and $69.4 \%$ were born in the USA. The mean depressive symptom score was $13 \cdot 3$ ( $\mathrm{SD} 4 \cdot 3$ ) and ranged from $5 \cdot 0$ to $25 \cdot 0$. The mean economic deprivation score was 0.02 (SD 1.01) and the range was -1.79 to 2.42 .

When identifying correlates of sweetened beverage consumption (Table 2), older students (aged 17-19 years) in comparison to younger students (aged 14-6 years) were more likely to drink soda daily. Asians in comparison to whites, and immigrants who arrived $>4$ years ago in comparison to US-born students, were significantly less likely to consume soda daily. When identifying correlates for fruit drink consumption, black, Hispanic and students from other racial backgrounds, in comparison to white students, were significantly more likely to consume fruit drinks daily. When identifying correlates of no sweetened beverage consumption, immigrants who arrived $>4$ years ago, in comparison to US-born students, were significantly more likely to consume no soda in the previous week. Students who immigrated to the USA $>4$ years ago in comparison to US-born students, and those from moderately deprived neighbourhoods in comparison to those from low deprived neighbourhoods, were significantly more likely to consume no fruit drinks. These findings provide support that the demographic profiles of soda and fruit drink consumers differ.

The results of models for the relationship between soda/fruit drink consumption and depressive symptoms are presented in Table 3. When soda consumption was the 
main exposure of interest, the adjusted model using imputed data indicated that compared with those who reported never consuming soda, there was no significant

Table 1 Characteristics of the adolescents participating in the Boston Youth Survey 2008, Massachusetts, USA

\begin{tabular}{|c|c|c|c|c|}
\hline & \multicolumn{2}{|c|}{ Case-complete } & \multicolumn{2}{|r|}{ Imputed } \\
\hline & $n$ & Proportion (\%) & $n$ & Proportion (\%) \\
\hline \multicolumn{5}{|l|}{ Gender } \\
\hline Male & 579 & $44 \cdot 1$ & 736 & $45 \cdot 7$ \\
\hline Female & 735 & 55.9 & 875 & $54 \cdot 3$ \\
\hline \multicolumn{5}{|l|}{ Race } \\
\hline White & 126 & $9 \cdot 6$ & 136 & $8 \cdot 4$ \\
\hline Black & 544 & 41.4 & 683 & $42 \cdot 4$ \\
\hline Asian/South Asian & 109 & 8.3 & 130 & $8 \cdot 1$ \\
\hline Hispanic & 443 & 33.7 & 549 & $34 \cdot 1$ \\
\hline Other & 92 & $7 \cdot 0$ & 113 & $7 \cdot 0$ \\
\hline \multicolumn{5}{|l|}{ Nativity } \\
\hline New immigrant & 107 & $8 \cdot 1$ & 157 & $9 \cdot 7$ \\
\hline Settled immigrant & 263 & $20 \cdot 0$ & 332 & $20 \cdot 6$ \\
\hline Born in USA & 944 & 71.8 & 1122 & 69.6 \\
\hline \multicolumn{5}{|l|}{ Age (years) } \\
\hline 13 or 14 & 107 & $8 \cdot 1$ & 133 & $8 \cdot 3$ \\
\hline 15 & 262 & 19.9 & 316 & $19 \cdot 6$ \\
\hline 16 & 357 & $27 \cdot 2$ & 438 & $27 \cdot 2$ \\
\hline 17 & 356 & $27 \cdot 1$ & 422 & $26 \cdot 2$ \\
\hline 18 & 178 & $13 \cdot 6$ & 225 & 14.0 \\
\hline 19 & 178 & $13 \cdot 6$ & 77 & $4 \cdot 8$ \\
\hline \multicolumn{5}{|l|}{ Soda consumption } \\
\hline Never & 307 & 23.4 & 346 & 21.5 \\
\hline 1 time/week & 287 & $21 \cdot 8$ & 334 & $20 \cdot 7$ \\
\hline 2-6 times/week & 424 & $32 \cdot 3$ & 597 & $37 \cdot 1$ \\
\hline$\geq 1$ times $/ \mathrm{d}$ & 296 & $22 \cdot 5$ & 334 & $20 \cdot 7$ \\
\hline \multicolumn{5}{|c|}{ Fruit drink consumption } \\
\hline Never & 248 & $19 \cdot 1$ & 276 & $17 \cdot 1$ \\
\hline 1 time/week & 196 & $15 \cdot 1$ & 242 & $15 \cdot 0$ \\
\hline 2-6 times/week & 474 & $36 \cdot 5$ & 636 & 39.5 \\
\hline$\geq 1$ times $/ \mathrm{d}$ & 382 & 29.4 & 457 & 28.4 \\
\hline
\end{tabular}

difference in depressive scores among those who consumed soda 1 time/week ( $\beta=-0 \cdot 04 ; 95 \%$ CI $-0 \cdot 18,0 \cdot 10)$. However, those who consumed soda $2-6$ times/week $(\beta=0 \cdot 18 ; 95 \%$ CI $0 \cdot 04,0 \cdot 32)$ and $\geq 1$ times/d $(\beta=0 \cdot 29$; $95 \%$ CI $0.13,0.45)$ had significantly greater depressive scores. A marginally significant linear trend between amount of soda consumed and depressive scores was observed ( $P=0.09$; Fig. 1(a)).

When fruit drink consumption was the main exposure, similar findings were obtained. For example, in comparison to students who reported never consuming fruit drinks, those who drank fruit drinks 2-6 times/week $(\beta=0 \cdot 14 ; 95 \%$ CI $0.00,0.28)$ and $\geq 1$ times/d ( $\beta=0.22 ; 95 \%$ CI $0.04,0 \cdot 40)$ had significantly greater depressive scores. A significant positive linear trend was observed $(P=0 \cdot 02$; Fig. 1(b)).

Neither race $\times$ sweetened beverage consumption, gender $\times$ sweetened beverage consumption, nor the cross-level economic deprivation $\times$ sweetened beverage consumption interaction terms were significant (data not shown). Therefore, the association between sweetened beverage consumption and depressive symptoms did not differ across racial groups and genders.

\section{Discussion}

The current investigation is one of the first to investigate the association between sweetened beverage consumption and depressive symptoms among adolescents. These findings are consistent with other studies among adults $^{(17-19)}$ and with studies that indicate increased sugar intake is related to an increased risk of depression ${ }^{(28-32)}$.

Table 2 The relationship of sociodemographic characteristics with beverage consumption among adolescents ( $n$ 1611) participating in the 2008 Boston Youth Survey, Massachusetts, USA

\begin{tabular}{|c|c|c|c|c|c|c|c|c|}
\hline & \multicolumn{2}{|c|}{$\begin{array}{l}\text { Daily soda } \\
\text { consumption }\end{array}$} & \multicolumn{2}{|c|}{$\begin{array}{l}\text { Daily fruit drink } \\
\text { consumption }\end{array}$} & \multicolumn{2}{|c|}{$\begin{array}{l}\text { No daily soda } \\
\text { consumption }\end{array}$} & \multicolumn{2}{|c|}{$\begin{array}{l}\text { No daily fruit drink } \\
\text { consumption }\end{array}$} \\
\hline & $\beta$ & $95 \% \mathrm{Cl}$ & $\beta$ & $95 \% \mathrm{Cl}$ & $\beta$ & $95 \% \mathrm{Cl}$ & $\beta$ & $95 \% \mathrm{Cl}$ \\
\hline \multicolumn{9}{|l|}{ Gender } \\
\hline Male (ref.) & \multicolumn{2}{|r|}{1.00} & \multicolumn{2}{|c|}{1.00} & \multicolumn{2}{|c|}{1.00} & \multicolumn{2}{|c|}{1.00} \\
\hline Female & 0.89 & $0.69,1 \cdot 14$ & 0.95 & $0.75,1.21$ & 1.23 & $0.94,1.60$ & 1.28 & $0.97,1.68$ \\
\hline \multicolumn{9}{|l|}{ Age (years) } \\
\hline $14-16$ (ref.) & \multicolumn{2}{|r|}{1.00} & \multicolumn{2}{|c|}{1.00} & \multicolumn{2}{|c|}{1.00} & \multicolumn{2}{|c|}{1.00} \\
\hline $17-19$ & 1.32 & $1.05,1.66^{\star}$ & $1 \cdot 24$ & $1.01,1.52^{\star}$ & 0.82 & $0.65,1.02$ & 0.67 & $0.52,0.85^{*}$ \\
\hline \multicolumn{9}{|l|}{ Race } \\
\hline White (ref.) & \multicolumn{2}{|r|}{1.00} & \multicolumn{2}{|c|}{1.00} & \multicolumn{2}{|c|}{1.00} & \multicolumn{2}{|c|}{1.00} \\
\hline Black & 1.00 & $0.68,1.47$ & 3.80 & $2 \cdot 61,5 \cdot 53^{*}$ & 0.54 & $0.35,0.83^{*}$ & 0.23 & $0.15,0.34^{*}$ \\
\hline Hispanic & 1.02 & $0.71,1.46$ & 1.96 & $1 \cdot 37,2 \cdot 81$ & 0.36 & $0.25,0.53^{*}$ & 0.27 & $0.19,0.40^{*}$ \\
\hline Asian & 0.25 & $0.14,0.44^{*}$ & 0.57 & $0.33,1.00$ & 1.38 & $0 \cdot 86,2 \cdot 21$ & 1.05 & $0.66,1.65$ \\
\hline Other & 0.82 & $0.48,1.42$ & $2 \cdot 21$ & $1 \cdot 30,3 \cdot 76^{*}$ & 0.71 & $0.44,1 \cdot 14$ & 0.32 & $0.17,0.58^{\star}$ \\
\hline \multicolumn{9}{|l|}{ Nativity } \\
\hline US-born (ref.) & \multicolumn{2}{|r|}{1.00} & \multicolumn{2}{|c|}{1.00} & \multicolumn{2}{|c|}{1.00} & \multicolumn{2}{|c|}{1.00} \\
\hline Arrived $>4$ years ago & 0.68 & $0.49,0.96^{*}$ & 0.71 & $0.53,0.94^{*}$ & 1.47 & $1.09,1.99^{*}$ & 1.53 & $1 \cdot 13,2 \cdot 07^{*}$ \\
\hline \multirow{2}{*}{\multicolumn{9}{|c|}{ Neighbourhood deprivation }} \\
\hline & & & & & & & & \\
\hline Low (ref.) & \multicolumn{2}{|r|}{1.00} & \multicolumn{2}{|c|}{1.00} & \multicolumn{2}{|c|}{1.00} & \multicolumn{2}{|c|}{1.00} \\
\hline Moderate & 1.08 & $0.81,1.43$ & 0.90 & $0.73,1.11$ & 1.23 & $0.98,1.53$ & 1.38 & $1.03,1.84^{*}$ \\
\hline High & 0.90 & $0.64,1.27$ & $1 \cdot 13$ & $0.91,1.42$ & $1 \cdot 18$ & $0.92,1.50$ & 1.00 & $0.76,1.30$ \\
\hline
\end{tabular}

Ref., reference category.

*Indicates a significant predictor at $P<0.05$. 
Table 3 The relationship of soda, fruit drink and overall sweetened beverage consumption with depressive symptoms among adolescents $(n$ 1611) participating in the 2008 Boston Youth Survey, Massachusetts, USA

\begin{tabular}{|c|c|c|c|c|c|c|c|c|c|c|c|c|}
\hline & \multicolumn{4}{|c|}{ Soft drink consumption } & \multicolumn{4}{|c|}{ Fruit drink consumption } & \multicolumn{4}{|c|}{ Sweetened beverage consumption } \\
\hline & \multicolumn{2}{|r|}{ Crude } & \multicolumn{2}{|c|}{ Adjusted } & \multicolumn{2}{|r|}{ Crude } & \multicolumn{2}{|c|}{ Adjusted } & \multicolumn{2}{|r|}{ Crude } & \multicolumn{2}{|c|}{ Adjusted } \\
\hline & $\beta$ & $95 \% \mathrm{Cl}$ & $\beta$ & $95 \% \mathrm{Cl}$ & $\beta$ & $95 \% \mathrm{Cl}$ & $\beta$ & $95 \% \mathrm{Cl}$ & $\beta$ & $95 \% \mathrm{Cl}$ & $\beta$ & $95 \% \mathrm{Cl}$ \\
\hline \multicolumn{13}{|l|}{ Consumption } \\
\hline Never (ref.) & & 1.00 & & 1.00 & & 1.00 & & 1.00 & & 1.00 & & 1.00 \\
\hline 1 time/week & -0.05 & $-0.21,0.11$ & -0.04 & $-0.18,0.10$ & 0.06 & $-0.12,0.24$ & 0.03 & $-0.15,0.21$ & 0.00 & $-0.22,0.22$ & -0.01 & $-0.02,0.42$ \\
\hline 2-6 times/week & 0.15 & $0.01,0.29^{\star}$ & 0.18 & $0.04,0.32^{*}$ & 0.08 & $-0.06,0.22$ & 0.14 & $0.00,0.28^{*}$ & 0.14 & $-0.05,0.33$ & 0.20 & $-0.02,0.42$ \\
\hline$\geq 1$ times $/ \mathrm{d}$ & 0.25 & $0.09,0.41^{*}$ & 0.29 & $0.13,0.45^{\star}$ & 0.17 & $0.01,0.33^{*}$ & 0.22 & $0.04,0.40^{*}$ & 0.25 & $0.05,0.44^{\star}$ & 0.31 & $0.09,0.54^{*}$ \\
\hline \multicolumn{13}{|l|}{ Gender } \\
\hline Male (ref.) & & & & 1.00 & & & & 1.00 & & & & 1.00 \\
\hline Female & & & 0.47 & $0.38,0.56$ & & & 0.47 & $0.27,0.67^{*}$ & & & 0.47 & $0.38,0.57^{*}$ \\
\hline \multicolumn{13}{|l|}{ Age (years) } \\
\hline 14 (ref.) & & & & 1.00 & & & & 1.00 & & & & 1.00 \\
\hline 15 & & & 0.14 & $-0.06,0.34$ & & & 0.15 & $-0.01,0.31$ & & & 0.15 & $0.01,0.30^{*}$ \\
\hline 16 & & & 0.23 & $0.05,0.41^{*}$ & & & 0.25 & $0.11,0.39^{\star}$ & & & 0.24 & $0.11,0.38^{\star}$ \\
\hline 17 & & & 0.17 & $-0.01,0.35$ & & & 0.18 & $0.04,0.32^{*}$ & & & $0 \cdot 18$ & $0.05,0.31^{*}$ \\
\hline 18 & & & 0.27 & $0.07,0.47^{\star}$ & & & 0.28 & $0.14,0.42^{*}$ & & & 0.29 & $0.15,0.42^{\star}$ \\
\hline 19 & & & 0.40 & $0.13,0.67^{\star}$ & & & 0.41 & $0.06,0.76^{\star}$ & & & 0.41 & $0.06,0.77^{*}$ \\
\hline \multicolumn{13}{|l|}{ Race } \\
\hline White (ref.) & & & & 1.00 & & & & 1.00 & & & & 1.00 \\
\hline Black & & & 0.02 & $-0.16,0.20$ & & & -0.03 & $-0.23,0.17$ & & & -0.04 & $-0.23,0.16$ \\
\hline Hispanic & & & 0.08 & $-0.10,0.26$ & & & 0.07 & $-0.13,0.27$ & & & 0.06 & $-0.15,0.26$ \\
\hline Asian & & & 0.1 & $-0.14,0.34$ & & & 0.07 & $-0.20,0.34$ & & & 0.09 & $-0.19,0.36$ \\
\hline Other & & & 0.2 & $-0.04,0.44$ & & & 0.17 & $-0.08,0.42$ & & & 0.17 & $-0.05,0.14$ \\
\hline \multicolumn{13}{|l|}{ Nativity } \\
\hline US-born (ref.) & & & & 1.00 & & & & 1.00 & & & & 1.00 \\
\hline Arrived $>4$ years ago & & & 0.05 & $-0.07,0.17$ & & & 0.04 & $-0.06,0.14$ & & & 0.04 & $-0.05,0.14$ \\
\hline Arrived $\leq 4$ years ago & & & -0.04 & $-0.22,0.14$ & & & -0.05 & $-0.23,0.13$ & & & -0.04 & $-0.22,0.13$ \\
\hline \multicolumn{13}{|l|}{ Neighbourhood deprivation } \\
\hline Low (ref.) & & & & 1.00 & & & & 1.00 & & & & 1.00 \\
\hline Moderate & & & -0.07 & $-0.21,0.07$ & & & -0.06 & $-0.18,0.06$ & & & -0.06 & $-0.18,0.07$ \\
\hline High & & & -0.09 & $-0.23,0.05$ & & & -0.09 & $-0.21,0.03$ & & & -0.09 & $-0.21,0.02$ \\
\hline
\end{tabular}

Ref., reference category.

*Indicates a significant predictor at $P<0.05$. 
(a)

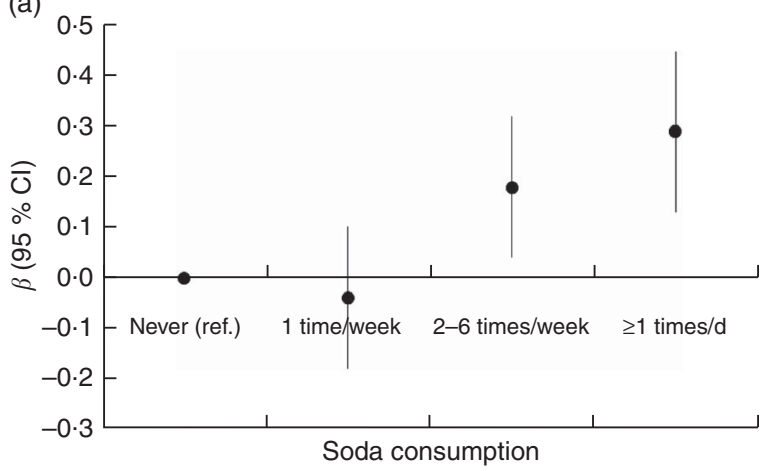

(b)

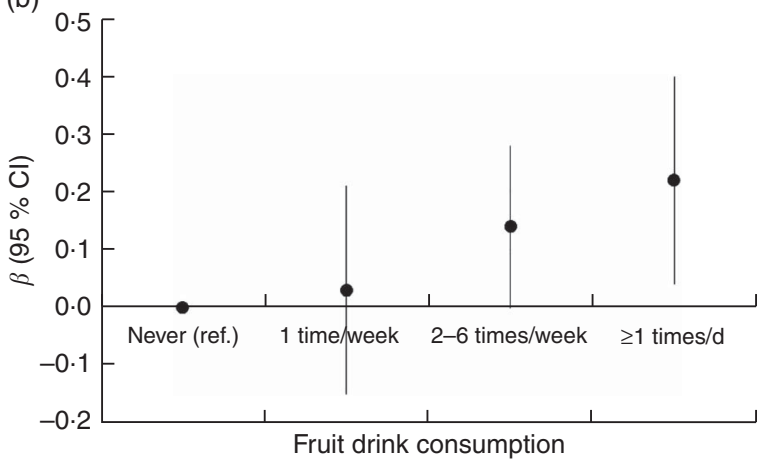

Fig. 1 The relationship of (a) soda consumption and (b) fruit drink consumption with depressive symptoms, controlling for individual and neighbourhood-level confounders, among adolescents ( $n$ 1611) participating in the 2008 Boston Youth Study, Massachusetts, USA. Values are $\beta$ estimates with their $95 \%$ confidence intervals represented by vertical bars (ref., reference category)

We found that there were some differences in sociodemographic characteristics between soda and fruit drink consumers. However, more frequent soda and fruit drink consumption were both associated with higher depressive symptoms after controlling for confounding variables. Overall, our results indicate that sweetened beverage consumption, which accounts for a high proportion of daily energy intake among US adolescents, might not only be detrimental to physical health, but also harmful to mental health.

Our investigation is consistent with several studies conducted among adults that indicate consumption of sweetened beverages is associated with depression ${ }^{(17-19)}$ as well with studies conducted among adolescents that indicate high intake of foods high in refined sugar is associated with increased risk for depression ${ }^{(28-32)}$. Our study adds to the literature because it is one of the first studies to identify the relationship of both soda and fruit drink consumption with depressive symptoms among adolescents. Adolescence is an important stage in human development and restricting sugar-sweetened beverage consumption may help healthy adolescent development.

Sweetened beverages contain high levels of refined sugar. Although public health professionals have focused mainly on sweetened beverage consumption and increased risk for obesity ${ }^{(33-35)}$, adverse effects of these beverages on other health outcomes have not been sufficiently addressed. The present results suggest that high consumption of sweetened beverages may also be associated with higher risk for depression. Two possible biological mechanisms have been proposed. First, refined sugar has been shown to suppress the growth hormone brain-derived neurotrophic factor, a decrease in normal functioning of which has been linked with depression ${ }^{(15,16)}$. Second, sugar consumption impairs glucose and lipid metabolism and promotes inflammation, which disrupts the normal functioning of the immune system and may lead to a greater risk for depression ${ }^{(36-38)}$. Sweetened beverage consumption increases risk for obesity, diabetes and other chronic illnesses, which in turn are risk factors for depression $^{(39,40)}$.

Public health professionals should not only emphasize the adverse risk of obesity that comes along with sweetened beverage consumption, but also warn parents, adolescents and policy makers about the potential negative effects these beverages can have on mental development and health. Policies that restrict the availability of sweetened beverages within schools and community and recreation centres while promoting the consumption of water might be beneficial to adolescent health. Since the sociodemographic profiles of soda and fruit drink consumers differ, public health practitioners could better identify those who are at greater risk of consuming different types of sweetened beverages.

These findings should be interpreted in light of the limitations of the present study. We used cross-sectional data to help us investigate the relationship between sweetened beverage consumption and depressive symptoms and therefore the temporality of main exposure and outcome could not be identified. However, our hypotheses and directionality have intuitive appeal and are based on previous work. Since individual-level covariates, such as household income, parental education or occupation, were not collected, residual confounding might be an issue. Furthermore, we did not measure dietary intake and therefore intake of foods high in refined sugar could not be accounted for. However, dietary behaviours tend to cluster and sweetened beverage consumption might be a good marker for overall dietary intake. Finally, we might be able to generalize the results to urban centres similar to Boston but not necessarily to non-urban areas.

An alternative explanation for the relationship between soft drink consumption and depression could be that it is the caffeine found within these beverages and not the sugar that increases the risk for depression. Several studies have identified caffeine consumption as related to depression. Researchers theorize that caffeine interferes with the dopaminergic and glutamatergic systems, which can lead to mood disorders ${ }^{(41-43)}$. Since the BYS did not distinguish between which beverages contained caffeine and which ones did not, we were not able to determine 
whether the sugar or caffeine was responsible for the relationship between sweetened beverages and depressive symptoms. However, we measured soda and fruit drink consumption separately. Since fruit drinks do not contain caffeine and consumption of these drinks was associated with increased depressive symptoms, we can deduce that our study contributed evidence to the possibility that sugar intake is associated with increased depressive symptoms.

\section{Conclusion}

In conclusion, findings from the present study suggest that sweetened beverage consumption is associated with depressive symptoms among adolescents living in an urban setting. Sweetened beverage consumption is potentially harmful to the development and mental health of adolescents. Further investigation should include longitudinal studies to determine whether sweetened beverage consumption is a predictor of depression among adolescents as they age into adulthood.

\section{Acknowledgements}

Acknowledgements: The BYS was conducted in collaboration with the Boston Public Health Commission (Barbara Ferrer, Director), Boston's Office of Human Services (Larry Mayes, Chief), Boston public schools (Dr Carol Johnson, then-Superintendent) and the Office of The then-Honourable Mayor, Thomas M. Menino. The survey would not have been possible without the participation of the faculty, staff, administrators and students of Boston Public Schools. Financial support: This work was supported by a grant from the Centers for Disease Control and Prevention (CDC), National Center for Injury Prevention and Control (NCIPC) (grant number U49CE00740) to the Harvard Youth Violence Prevention Center (D.H., Principal Investigator). This work was supported in part by cooperative agreements with the CDC (grant number U48DP001946). The funders had no role in the design, analysis or writing of this article. Conflict of interest: No financial disclosures were reported by the authors of this paper. Authorship: R.P. developed the research question and conceptual model, conducted the statistical analyses and was lead author. J.D. conducted the literature review and helped with writing the introduction and discussion for the paper. D.H. helped with the conceptual framework and helped write the manuscript. B.E.M. provided guidance, helped formulate the research question, provided input in the analytical strategy, and provided assistance in writing the manuscript. Ethics of buman subject participation: The Office of Human Research Administration at the Harvard School of Public Health approved all procedures for the BYS.

\section{References}

1. Perou R, Bitsko RH, Blumberg SJ et al. (2013) Mental health surveillance among children - United States, 2005-2011. MMWR Suppl 62, Suppl. 2, 1-35.

2. Eaton DK, Kann L, Kinchen S et al. (2008) Youth risk behavior surveillance - United States, 2007. MMWR Surveill Summ 57, issue 4, 1-131.

3. Eaton DK, Kann L, Kinchen S et al. (2012) Youth risk behavior surveillance - United States, 2011. MMWR Surveill Summ 61, issue 4, 1-162.

4. Kubik MY, Lytle LA, Birnbaum AS et al. (2003) Prevalence and correlates of depressive symptoms in young adolescents. Am J Health Behav 27, 546-553.

5. Goodman E, Slap GB \& Huang B (2003) The public health impact of socioeconomic status on adolescent depression and obesity. Am J Public Health 93, 1844-1850.

6. Duffey KJ \& Popkin BM (2007) Shifts in patterns and consumption of beverages between 1965 and 2002. Obesity (Silver Spring) 15, 2739-2747.

7. French SA, Lin BH \& Guthrie JF (2003) National trends in soft drink consumption among children and adolescents age 6 to 17 years: prevalence, amounts, and sources, 1977/ 1978 to 1994/1998. J Am Diet Assoc 103, 1326-1331.

8. Naska A, Bountziouka V, Trichopoulou A et al. (2010) Soft drinks: time trends and correlates in twenty-four European countries. A cross-national study using the DAFNE (Data Food Networking) databank. Public Health Nutr 13, 1346-1355.

9. Nelson MC, Neumark-Sztainer D, Hannan PJ et al. (2009) Five-year longitudinal and secular shifts in adolescent beverage intake: findings from Project EAT (Eating Among Teens)-II. J Am Diet Assoc 109, 308-312.

10. Rajeshwari R, Yang SJ, Nicklas TA et al. (2005) Secular trends in children's sweetened-beverage consumption (1973 to 1994): the Bogalusa Heart Study. J Am Diet Assoc 105, 208-214.

11. Solnick SJ \& Hemenway D (2012) The 'Twinkie Defense': the relationship between carbonated non-diet soft drinks and violence perpetration among Boston high school students. Inj Prev 18, 259-263.

12. Solnick SJ \& Hemenway D (2014) Soft drinks, aggression and suicidal behaviour in US high school students. Int J Inj Contr Saf Promot 21, 266-273.

13. Suglia SF, Solnick S \& Hemenway D (2013) Soft drinks consumption is associated with behavior problems in 5-year-olds. J Pediatr 163, 1323-1328.

14. Westover AN \& Marangell LB (2002) A cross-national relationship between sugar consumption and major depression? Depress Anxiety 16, 118-120.

15. Brunoni AR, Lopes M \& Fregni F (2008) A systematic review and meta-analysis of clinical studies on major depression and BDNF levels: implications for the role of neuroplasticity in depression. Int J Neuropsychopharmacol 11, 1169-1180.

16. Dwivedi Y (2009) Brain-derived neurotrophic factor: role in depression and suicide. Neuropsychiatr Dis Treat $\mathbf{5}$, 433-449.

17. $\mathrm{Yu} \mathrm{B}, \mathrm{He} \mathrm{H}$, Zhang Q et al. (2014) Soft drink consumption is associated with depressive symptoms among adults in China. J Affect Disord 172C, 422-427.

18. Guo X, Park Y, Freedman ND et al. (2014) Sweetened beverages, coffee, and tea and depression risk among older US adults. PLoS One 9 , e94715.

19. Shi Z, Taylor AW, Wittert G et al. (2010) Soft drink consumption and mental health problems among adults in Australia. Public Health Nutr 13, 1073-1079.

20. Lien L, Lien N, Heyerdahl S et al. (2006) Consumption of soft drinks and hyperactivity, mental distress, and conduct problems among adolescents in Oslo, Norway. Am J Public Health 96, 1815-1820. 
21. Pabayo R, Spence JC, Cutumisu N et al. (2012) Sociodemographic, behavioural and environmental correlates of sweetened beverage consumption among pre-school children. Public Health Nutr 15, 1338-1346.

22. Rothman EF, Johnson RM, Azrael D et al. (2010) Perpetration of physical assault against dating partners, peers, and siblings among a locally representative sample of high school students in Boston, Massachusetts. Arch Pediatr Adolesc Med 164, 1118-1124.

23. Hemenway D, Barber CW, Gallagher SS et al. (2009) Creating a National Violent Death Reporting System: a successful beginning. Am J Prev Med 37, 68-71.

24. Azrael D, Johnson RM, Molnar BE et al. (2009) Creating a youth violence data system for Boston, Massachusetts. Aust N Z J Criminol 42, 406-421.

25. Sterne JA, White IR, Carlin JB et al. (2009) Multiple imputation for missing data in epidemiological and clinical research: potential and pitfalls. BMJ 338, b2393.

26. Dunn EC, Johnson RM \& Green JG (2012) The Modified Depression Scale (MDS): a brief, no-cost assessment tool to estimate the level of depressive symptoms in students and schools. School Ment Health 4, 34-45.

27. Diez-Roux AV (2000) Multilevel analysis in public health research. Annu Rev Public Health 21, 171-192.

28. Kohlboeck G, Sausenthaler S, Standl M et al. (2012) Food intake, diet quality and behavioral problems in children: results from the GINI-plus/LISA-plus studies. Ann Nutr Metab 60, 247-256.

29. Oddy WH, Robinson M, Ambrosini GL et al. (2009) The association between dietary patterns and mental health in early adolescence. Prev Med 49, 39-44.

30. Oellingrath IM, Svendsen MV \& Hestetun I (2014) Eating patterns and mental health problems in early adolescence a cross-sectional study of 12-13-year-old Norwegian schoolchildren. Public Health Nutr 17, 2554-2562.

31. Zahedi H, Kelishadi R, Heshmat R et al. (2014) Association between junk food consumption and mental health in a national sample of Iranian children and adolescents: the CASPIAN-IV study. Nutrition 30, 1391-1397.

32. Zahra J, Ford T \& Jodrell D (2014) Cross-sectional survey of daily junk food consumption, irregular eating, mental and physical health and parenting style of British secondary school children. Child Care Health Dev 40, 481-491.

33. Martin-Calvo N, Martinez-Gonzalez MA, Bes-Rastrollo M et al. (2014) Sugar-sweetened carbonated beverage consumption and childhood/adolescent obesity: a case-control study. Public Health Nutr 17, 2185-2193.

34. Collison KS, Zaidi MZ, Subhani SN et al. (2010) Sugarsweetened carbonated beverage consumption correlates with BMI, waist circumference, and poor dietary choices in school children. BMC Public Health 10, 234.

35. Harrington S (2008) The role of sugar-sweetened beverage consumption in adolescent obesity: a review of the literature. J Sch Nurs 24, 3-12.

36. Miller GE \& Backwell E (2006) Turning up the heat: inflammation as a mechanism linking chronic stress, depression, and heart disease. Curr Dir Psychol Sci 15, 269-272.

37. Raison CL, Capuron L \& Miller AH (2006) Cytokines sing the blues: inflammation and the pathogenesis of depression. Trends Immunol 27, 24-31.

38. Aeberli I, Gerber PA, Hochuli M et al. (2011) Low to moderate sugar-sweetened beverage consumption impairs glucose and lipid metabolism and promotes inflammation in healthy young men: a randomized controlled trial. Am J Clin Nutr 94, 479-485.

39. Onyike CU, Crum RM, Lee HB et al. (2003) Is obesity associated with major depression? Results from the Third National Health and Nutrition Examination Survey. Am J Epidemiol 158, 1139-1147.

40. Anderson RJ, Freedland KE, Clouse RE et al. (2001) The prevalence of comorbid depression in adults with diabetes: a meta-analysis. Diabetes Care 24, 1069-1078.

41. Salim H, Ferre S, Dalal A et al. (2000) Activation of adenosine $\mathrm{A} 1$ and $\mathrm{A} 2 \mathrm{~A}$ receptors modulates dopamine D2 receptor-induced responses in stably transfected human neuroblastoma cells. J Neurochem 74, 432-439.

42. Fuxe K, Agnati LF, Jacobsen K et al. (2003) Receptor heteromerization in adenosine A2A receptor signaling: relevance for striatal function and Parkinson's disease. Neurology 61, 11 Suppl. 6, S19-S23.

43. Ciruela F, Casado V, Rodrigues RJ et al. (2006) Presynaptic control of striatal glutamatergic neurotransmission by adenosine A1-A2A receptor heteromers. J Neurosci 26, 2080-2087. 